\title{
DESIGN OF AN INTRODUCTORY ENGINEERING DESIGN AND COMMUNICATION COURSE WHICH INTEGRATES FIRST SEMESTER COURSES
}

\author{
Sanjeev Bedi, Carol Hulls, Chris Rennick, Mary Robinson, and William Melek \\ University of Waterloo \\ sbedi@uwaterloo.ca,chulls@uwaterloo.ca, crennick@uwaterloo.ca,mary.robinson@uwaterloo.ca, \\ william.melek@uwaterloo.ca
}

\begin{abstract}
In their first semester at UWaterloo, Mechatronics Engineering students take a course which introduces them to their chosen discipline, and which has a focus on communication skills (MTE 100 -Mechatronics Engineering). In 2010, a multi-year refresh of MTE 100 was initiated to address shortcomings in both the course, and the semester as a whole.

The first semester instructors have now completed the refresh of MTE 100. Multiple hands-on, integrative activities that connect the other first semester courses to MTE 100 were added throughout the first semester.

The introduction of these integrative activities has improved the first semester of the Mechatronics program. Survey data and feedback from end of term course critiques show an increased appreciation of foundational courses like Chemistry. From focus groups conducted with upper year students, there is a strong desire for similar experiences in upper years.
\end{abstract}

Keywords: First Year, Course Design, Active Learning, Institutional Culture

\section{INTRODUCTION}

The Mechatronics Engineering (MTE) program was introduced at the University of Waterloo in 2003. Waterloo's Engineering programs have mandatory co-op, and students in Mechatronics have their first work term after only 4 months of University (so-called 4-stream students), and then alternate every other term for a total of six work terms over their undergraduate degree. The last two consecutive terms (4A and 4B) are academic, allowing for an 8-month capstone project. In their first semester on campus, students take a mix of foundational math and science courses including algebra (Math 115), differential calculus (Math 116), and chemistry (CHE 102). Additionally, they take a programming course (which has been taught in $\mathrm{C}++$ ) - GENE 121, and an introduction to mechatronics course - MTE 100. Of these courses, Algebra, Calculus and Chemistry are very traditional courses taught to not only MTE students, but many other programs as well, and therefore are quite rigid in content, assessments, and structure. To move topics around inside of these courses would impact every other program, which involves more than 1500 students, and so is strongly discouraged.

MTE 100 is meant to serve as an introduction to both Mechatronics Engineering and the profession as a whole. The course is a one semester course which carries the weight of a course and a half. Of all the courses in first year, it is the one that is primarily responsible for setting the tone for what is to come for the remainder of the program. The course has two primary instructors: one with $35 \%$ of course deliverables focusing on Engineering Graphics and Design (AutoCAD, Solidworks, and hand drawing); and the other with the remaining $65 \%$ of course deliverables focussing on oral and written communication, engineering design, information on University services (co-op, library, etc.), and discipline-specific learning.

Incoming students in the MTE program have typical high school backgrounds with most having minimal exposure to software development, and little to no prior exposure of the other three threads of the program (mechanical design, electronics, and control systems). Identifying a platform that allows students to experience all four components, without bogging them down in fine details, has always been difficult. The LEGO RCX was chosen as a platform as it allowed students to quickly construct their physical system and to work with motors and sensors to accomplish a task without having to worry about electronics, communication protocols, raw sensor data, etc. For the first few years, the project was highly constrained, and integration between courses was limited to having one of the programming TAs give an introduction to the specifics of programming the RCX brick. Students did not receive feedback on their software, as it was not graded.

The first class graduated from Mechatronics Engineering at Waterloo in 2008. By 2010, in response to issues raised by the first graduating classes in their exit surveys, and in response to issues identified by an internal report released by the First Year Engineering office, an update to the course was required. 
There were four identified issues:

1. the first year courses lacked active, hands-on learning opportunities, and the assessments were inauthentic;

2. students were struggling to see the connections between their different courses;

3. student engagement was weak, with many students asking the same question: "Why are we taking this course?"; and

4. the first year of the program was lacking an opportunity for students to ask and answer: "Is Mechatronics Engineering for me?"

To begin addressing these issues, the first semester MTE course instructors began experimenting with handson activities that integrate course concepts.

This paper describes these integration initiatives from the perspective of the primary host course: MTE 100. Results of the initiative are presented, and the challenges and successes the teaching team have experienced while implementing them will be discussed. This paper does not describe the specific activities as they have been written about previously [1] [2] [3] [4].

\subsection{Integration Initiatives at Other Institutions}

Educational initiatives that integrate material from multiple courses are not a new idea. The concept has existed in undergraduate curricula, both in, and outside of engineering programs for decades. In the United States, Harvey Mudd College's Engineering Clinic has been successfully running since the late 1960's, for example [5]. The 1990's saw the formation of several NSF-funded American University/College coalitions with the intent to improve first-year engineering curricula, many of whom introduced integrated curricula [6]. Froyd and Ohland characterized integrated curricula, and summarized the state of such programs in the US in 2005 [7]. Even within Canada, these sorts of programs have existed in different forms for years, with Mech 2 at UBC as the most visible example within Engineering [8]. In other faculties, the University of Guelph has been running an integrated Math and Physics first year curriculum since 2012 [9], and UBC has their Science One program [10].

These integration initiatives take many different forms, Al-Holou et al [6] characterized the course structure models as:

1. Separate Courses: individual courses retain their independent departmental structure

2. Course pairs/triads: two or three courses are coupled together, so a student registered in one is registered in all

3. Large course block: students take the entire course block simultaneously

Al-Holou et al also identified two ways that time can be shared between courses in an integrated curriculum:
1. Real-time sharing: faculty agree to adjust time shared among courses on a regular basis during the term. In this model, one course may get more hours one week, and fewer in a different week

2. Fixed-time allocation: faculty agree to allocate a fixed amount of time each week to each course

The initiative undertaken by the authors of this paper is that of separate courses with fixed-time allocation, with integration achieved using inquiry- and problem-based learning activities. Occasionally, one of the other course instructors will provide a lecture in MTE 100 to strengthen the connection to their own course.

It is important to note here that MTE 100 is very much the host of these activities (i.e. MTE 100 largely provides the grades, lab space, course time, etc.), with connections spreading into the other $1 \mathrm{~A}$ courses. This form of integration creates both a strength and a weakness to the initiatives undertaken. As the activities do not appear in the course calendar descriptions, their existence in a particular course is at the whim of that term's instructor. The strength of this is that the changes were relatively easy to initiate as no formal approval process was required. This also allows for great flexibility to change the nature of the integration (in quantity, complexity, courses involved, etc.) when the instructors so desire.

\section{EXPERIMENTS IN COURSE INTEGRATION (2011-2016)}

\subsection{Open-Ended Projects (2010-2011)}

As the first step in the re-design of MTE 100, for the fall 2010 term an Arduino-based platform was developed which would allow students to interact with built-in buttons, LEDs, motors, and sensors. As one of the MTE 100 labs, students were given parts from which they could implement a bump sensor for the front of the box. Although very limited in scope, students were excited about the opportunity to explore how to implement this part of the system on their own. When surveyed in fourth year, several students favourably recalled this part of MTE 100.

As the Arduino is programmed using $\mathrm{C} / \mathrm{C}++$, there were obvious links between the material in MTE 100 and the programming course. After some discussion, the course instructors agreed that writing a program to blink the LEDS and to control the H-bridge for the motors could be used as one of the weekly programming assignments. A second assignment involved using bit-wise operators.

Some aspects of the approach were a success. Offering joint activities that were partly assessed in one course and partly assessed in another was shown to be feasible and the concept of course integration was well received by the students. However, more work was required in terms of coordination for the teaching team, although this was mitigated by the fact that many of the topics taught in MTE 
100 can be delivered in any order, and so the MTE 100 schedule could be arranged to match that of the programming course at critical common points.

Reliability of the equipment was the largest problem encountered. Operation of the equipment was unclear, and it was not built to operate for long hours at a time. The platform was used for the MTE 100 course project, which was still line following, during which time the heavy use caused the wheels to literally fall off. In addition, writing low-level code proved to be a difficult task for beginning programmers, and helping students to debug the code was difficult. As a result, the second programming assignment was changed to be an optional bonus assignment.

In spite of the problems, the course instructors considered the approach to be a success. Surviving the difficulties associated with the assignments and end of term project had meant that the instructors became very comfortable with having to exercise "Plan B". This in turn reduced the fear surrounding experimentation going forward as the teaching team now had a good idea as to the types of things that could go wrong, and how to fix them. So the decision was made to continue revising MTE 100, but that reliability of any equipment used for activities was to be a key factor.

\subsection{Horizontal Integration Initiatives (2011- 2012)}

Fall 2011 saw the integration initiatives expand to bridge the $1 \mathrm{~A}$ Chemistry course using a project relating to fuel cell cars. In fall 2012, a Lego NXT-based course project, which replaced the Arduino equipment to bridge MTE 100 and Programming, was introduced to the course. Both of these initiatives were very successful, with great response from students and instructors alike. For full descriptions of these initiatives, refer to the original papers by Hulls et al. [2] [3]. Figure 1 below shows a timeline of when integrative activities were introduced, and in some cases, when they ended.

\subsection{Integrating Calculus and Algebra (2012)}

Buoyed by the success of the integration initiatives with Chemistry and Programming, instructors of the first semester Calculus and Algebra courses were approached to gauge their interest in activities that would integrate their courses with MTE 100 and GENE 121.

Mathematics examples are often used in programming courses because students are usually familiar with the example and so can focus on coding the algorithm. It also serves to provide students with extra practice or review of the particular mathematical concept. When the concept is introduced first in programming however, the approach does not work. It means the programming instructor has to teach the math, and subtly shifts the balance from mathematics being a tool in service of engineering, to programming being the tool for mathematics.

The math courses taught in the $1 \mathrm{~A}$ term are common to most of the engineering programs on campus, thus there is little scope for customization for a given program without going to the step of using a calendar change to introduce a separate course for the program (an approach that was taken by some departments at UWaterloo). However, as the teaching team was able to work around similar limitations for the chemistry course, there was cause for optimism that some sort of closer integration could be achieved that links the courses through examples and assignments. In preparation for the fall 2012 term, the math instructors met with the engineering instructors to identify connections between the courses, and identified two concepts: Newton's method for root finding, and the use of matrices as coordinate transforms.

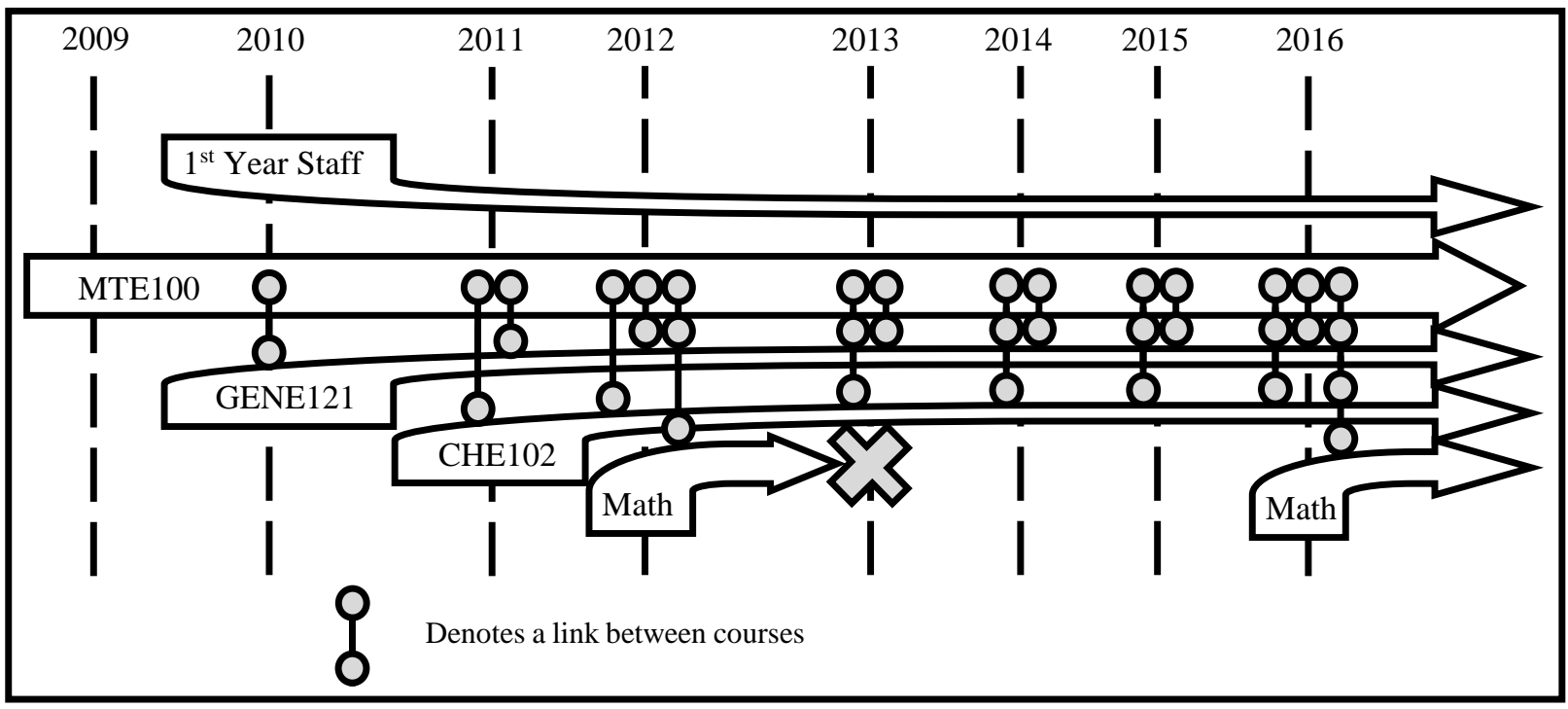

Figure 1 Map of horizontal integration activities 
While Newton's method requires iteration and so would be an appropriate exercise for coding loops, its placement in the calculus course made the integration impractical. Loops are taught in week three of the programming course, but Newton's method would not be taught until week five. So instead, Newton's method was used as an assignment question in programming near the end of term and students were told to refer back to their calculus notes. The result was ineffective. Too much time had elapsed between when Newton's method was taught in calculus and when it was used in programming, and in particular students were unprepared to return to a pre-midterm concept that was not being tested in calculus for the final exam.

Integrating coordinate transform matrices required even more effort. First, the introduction to objects (to allow the use of a simple graphics class) was moved forward in the term to synchronize with when the topic was taught in the algebra course. Second, one and a half lectures in MTE 100 on using transform matrices were delivered by the MTE 100 instructor. While the plan appeared to be reasonable, it turned out to be a failure in practice. Moving introduction to objects that early in the programming course proved to be a poor choice with regards to teaching the material as it had to be re-taught later in the term. In addition, there was a mismatch in terms of the level of difficulty between the algebra material taught in MTE 100 and used on the programming assignment compared to the level at which it was taught during the algebra course. This meant students needed a great deal of support to complete the programming assignment questions.

There were two lessons learned from attempting to integrate concepts that term. The first is that there needs to be a close synchronization in terms of when the material is taught in one course, and used in another course. For integration with MTE 100 and another course this is relatively easy as MTE 100 has a great deal of flexibility in terms of when topics are taught and so it is easy to rearrange topics (as was done for CHE 102-MTE 100 and GENE 121-MTE 100 integration). However, for integration between separate courses which have rigid schedules (because of the way that the course material progresses during the term), it may not be possible to integrate effectively. The second lesson is that consideration needs to be given as to who is developing and delivering the material. Having the Chemistry instructor add chemistry related examples to MTE 100 that aided understanding in her course worked well. Having the MTE 100 instructor produce the algebra examples did not aid in understanding for that course. Each instructor is most familiar with the key concepts in their own course, and so they need to be the leader when it comes to example applications. Fortunately, with MTE 100 as the main host course, it is not an issue to have one of the other instructors deliver some material as the course has many guest lecturers throughout the term. It does however produce an extra burden of that time on the other instructor as a trade- off against increased understanding as to why material is included in the curriculum.

\subsection{Tron Days (2016)}

While the initial attempts to integrate the first semester Math courses with MTE 100 were unsuccessful, there continued to be a strong desire to do so. When the first semester teaching team entered into meetings in December 2015 to discuss the future of MTE 100, a new idea was born for how to integrate Math with Engineering. The teaching team decided on the concept of a 2-day Hackathon-like event where students are given large, ambiguous problems with strong connections to all first semester courses. This event, which we called "Tron Days" was offered for the first time in October 2016. A full description of the event is available in Li, Rennick, Hulls et al. [1]

\section{RESULTS}

This section will present the results from the broader initiative of integrating material to improve student experiences in their 1A term, and in MTE 100 specifically; the results of the individual activities are presented in the original papers on those initiatives [1] [2] [3] [4].

The initial intention of this work was to address four issues:

1. the first year courses lacked active, hands-on learning opportunities, and the assessments were inauthentic;

2. students were struggling to see the connections between their different courses;

3. student engagement was weak, and

4. the first year of the program was lacking an opportunity for students to ask and answer: "Is Mechatronics Engineering for me?"

The many active learning activities that the authors have introduced address the first issue. The success of these initiatives led to the creation of the NSERC-sponsored Chair in IDEAs (Interactive Design Engineering Activities) with Dr. Bedi as the Chair holder. In some cases, the individual activities have now been expanded widely across the Faculty of Engineering. For example, 600 students in four programs participate in the keychainmaking activity every fall; a version of the fuel cell car activity is now being spread to all enrolled sections of CHE 102 ( 1400 students in 10 programs); and the second semester of the Mechanical Engineering program was altered to create a large integrated course which ends in a robotics project.

In every semester since 2013, a survey is delivered online after courses have ended. Table 1 below summarizes one measure of authenticity taken from this end of term survey: students are asked whether their 1A

CEEA17; Paper 034

University of Toronto; June 4-7, 2017 
course project could help a first year student find a co-op job, with nearly $80 \%$ in agreement in 2016 .

Table 1 Student response to "I think the lego project could help a first year student find a co-op job"

\begin{tabular}{|l|l|l|}
\hline & $\mathbf{2 0 1 5}$ & $\mathbf{2 0 1 6}$ \\
\hline Strongly Disagree & $5(3.2 \%)$ & $3(1.7 \%)$ \\
\hline Disagree & $9(5.8 \%)$ & $8(4.7 \%)$ \\
\hline Neutral & $33(21.4 \%)$ & $23(13.4 \%)$ \\
\hline Agree & $64(41.6 \%)$ & $69(40.1 \%)$ \\
\hline Strongly Agree & $43(27.9 \%)$ & $68(39.5 \%)$ \\
\hline
\end{tabular}

The second issue, of students failing to see the connections between their different $1 \mathrm{~A}$ courses, has been partially addressed. The authors are optimistic that Tron Days will further address this issue, however Tron Days has run only once, so it is difficult to definitively say the issue has been resolved. As a baseline moving forwards, Table 2 summarizes student feedback from a departmental exit survey students are given as they graduate. These years represent student $1 \mathrm{~A}$ terms of fall 2007 through fall 2011 with a graduating class size in all years of approximately 100-120 students. The integrated robotics project was delivered to the 2015 and 2016 classes, and the integrated fuel cell car project was delivered to the 2016 class. Clearly more work is required to address student satisfaction in their first Chemistry course.

Table 2 Graduating student exit survey: CHE 102 listed as worst/least important course

\begin{tabular}{|l|l|}
\hline $\begin{array}{l}\text { Graduating } \\
\text { Year }\end{array}$ & $\begin{array}{l}\text { \# students, worst/least } \\
\text { important course }\end{array}$ \\
\hline 2012 & $22(\mathrm{n}=51)$ \\
\hline 2013 & $9(\mathrm{n}=98)$ \\
\hline 2014 & $14(\mathrm{n}=87)$ \\
\hline 2015 & $3(\mathrm{n}=30)$ \\
\hline 2016 & $5(\mathrm{n}=47)$ \\
\hline
\end{tabular}

The hands-on integrative activities have come to define the $1 \mathrm{~A}$ term for both students and their instructors. To the 1A students, they represent the entirety of their "worldview" with regards to the discipline. This view is shared widely, to the extent that even potential students are aware of the activities, and in the case of the course project, some have started to mention this as a reason for choosing Mechatronics at UWaterloo on their supplementary application form. In regards to student engagement, the activities provide a greater opportunity for students to engage with the instructors beyond what is defined by the curriculum. There is a greater interest sparked by the nature of the activities, and coupled with this, the atmosphere lends itself to interesting discussions.

In focus groups conducted with upper year MTE students, one message was clear: they want more openended, integrative course projects. Students from the class of 2016 commented that working with the Lego sensors and motors on the $1 \mathrm{~A}$ course project was a good introduction to mechatronics systems, but that there was a lack of open-ended projects until the end of their third year.

Overall student perceptions of their 1A courses are summarized in Figure 2 and Figure 3 below. This data is taken from end of term course critiques. UWaterloo takes the raw student responses and normalizes them to a 100point scale. Figure 2 and Figure 3 are "centre-weighted" in this normalization, i.e. the ideal student response is the middle answer in the range (very easy to very difficult for Figure 2, and very little to very heavy for Figure 3). Two further explanations are needed: A second class of MTE students was introduced in 2014, and the CHE 102 data for 2014 and 2016 are not shown as the normal course instructor was on leave for both semesters. The GENE 121 instructor has remained the same over this period, and the MTE 100 instructors have alternated between the same two instructors, including two terms where they co-taught the course (2014 and 2015).

\section{Difficulty of Concepts}

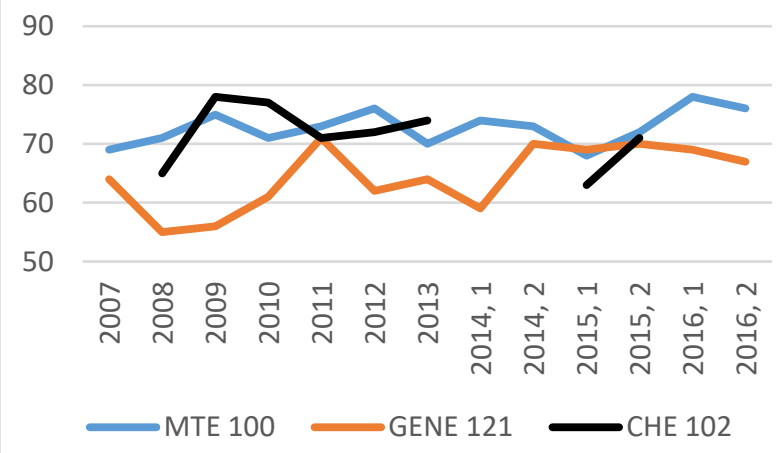

Figure 2 Student perception of difficulty of concepts from course critiques

\section{Workload}

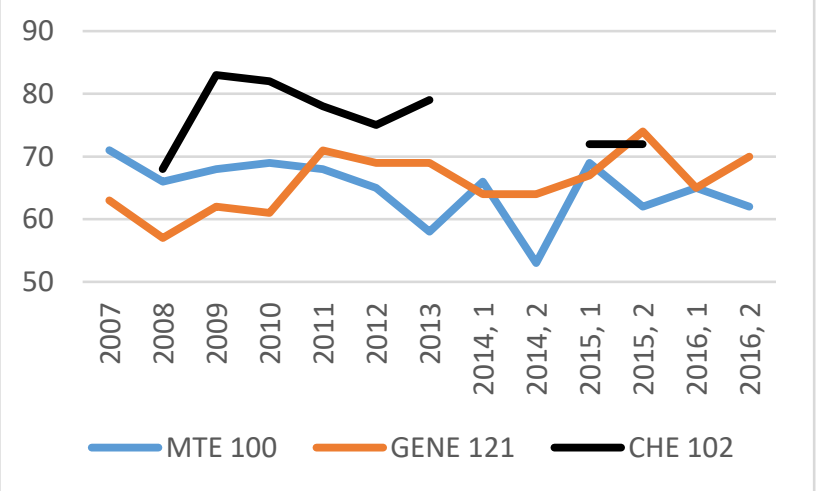

Figure 3 Student perception of workload from course critiques

CEEA17; Paper 034

University of Toronto; June 4-7, $2017 \quad-5$ of 8 - 
Neither graph shows much difference in student perception over the nearly 10 years of data, which when taken into the context of the term, is quite interesting. The scope of the project has absolutely increased since fall 2009: it has grown from a 3-hour lab where they programmed a pre-configured piece of hardware to follow a line on an obstacle course, to a 5 week open-ended project with scaffolded deliverables, multiple submissions, and checkpoints. Additionally, the amount of content taught in the term is largely unchanged (pre-2011, GENE 121 covered more advanced $\mathrm{C}++$ which was removed to make space for RobotC and the project). Yet, the student selfreported workload has not appreciably changed from 2007 to now. The teaching team suspects this is largely due to how we handle deliverables in the integrated courses. Students will create and submit one deliverable that the teaching team marks for multiple courses. For example, the course project report is marked by the MTE 100 TAs for format, mechanical design, and the design process. The report is then marked a second time by the GENE 121 TAs for programming design, and the quality of their project software.

At the instructor level, Figure 4 below presents the student perception of the quality of teaching they received from their course instructor.

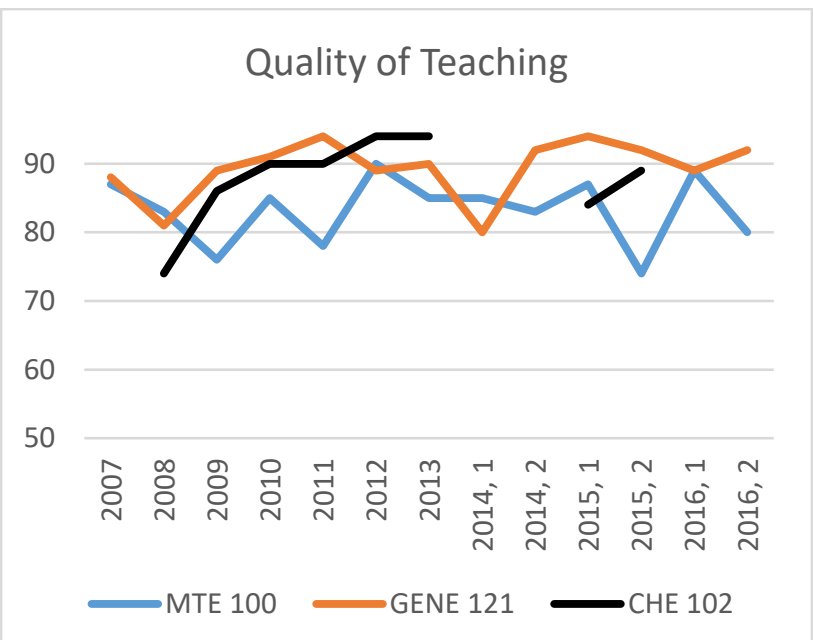

Figure 4 Student perception of quality of teaching from course critiques

Clearly, the increase in workload, and the added experimentation in all three courses has had no detrimental effect on teaching evaluations.

Changes in regards to the fourth identified issue are difficult to measure directly as indicators such as retention rate do not answer the correct question. To measure the impact of course changes on this fourth issue, the authors added a question to the end of term surveys given to the $1 \mathrm{~A}$ MTE students in fall 2015 and 2016. The students were asked to what level they agree with the following question: "I am confident I am in the correct program". Results from this question are summarized in Table 3 below. With our efforts, we are trying to reduce, or even eliminate the neutral answer: a student who knows they are in the correct program, or who knows they are in the wrong program and who can now search for the correct one, are more desirable moving in to upper years of the program. The authors find it interesting that even with the introduction of Tron Days, the percentage who responded with a neutral answer has not changed from 2015.

Table 3 Student response to "I am confident I am in the correct program"

\begin{tabular}{|l|l|l|}
\hline & $\mathbf{2 0 1 5}$ & $\mathbf{2 0 1 6}$ \\
\hline Strongly Disagree & $2(1.3 \%)$ & $1(0.6 \%)$ \\
\hline Disagree & $6(3.9 \%)$ & $6(3.5 \%)$ \\
\hline Neutral & $25(16.1 \%)$ & $28(16.3 \%)$ \\
\hline Agree & $64(41.3 \%)$ & $59(34.3 \%)$ \\
\hline Strongly Agree & $56(36.1 \%)$ & $77(44.8 \%)$ \\
\hline
\end{tabular}

\section{DISCUSSION}

The path taken by the 1A MTE teaching team over the last 7 years is not a conventional one, nor is it necessarily the exact path others should follow, however it has led to very positive change in the department, and in the broader Faculty of Engineering. When the experimentation began in 2010, it was to address identified issues in the first year curriculum, but there was hesitation towards implementing the proposed changes. Instructors are fiercely protective of their own material, its importance, and usefulness for their students, and for good reason. When courses are integrated, if the initiative fails, and there is no solid plan $\mathrm{B}$, it can have a huge impact on the students as they progress through their degree. It was certainly with great caution that the integration initiatives described in this paper were started. Instructors on both sides of the integration activity had concrete plans of how to back out should things begin to fall apart, and the initial integration activities were small in scope (both in student grades, and time commitment). The core belief in making all of these changes is to improve the student learning in $1 \mathrm{~A}$, and so students should not be harmed by any course changes.

A number of factors contributed to the success of these initiatives: stable, experienced instructors in the courses core to the initiative, heavy involvement from the program director throughout, experienced instructional staff, and perhaps most importantly, a flexible host course in MTE 100. Introductory courses such as MTE 100 have a lot of material to cover, but it is often non-cumulative, and so order of topics is not critical for student appreciation and understanding (e.g. students can learn about ethics before intellectual property and after the engineering design cycle, or in the reverse order with little confusion). Were MTE 100 more rigid, or were it to have instructors less comfortable with last minute changes, the course integration may have struggled to succeed. The initial

CEEA17; Paper 034

University of Toronto; June 4-7, 2017 
integration with Math was ultimately unsuccessful because of issues with progression of topics in rigid courses. To create an interesting assignment that integrated algebra and programming, the programming instructor rearranged topics in their course, which ultimately had a negative impact on how students learned the programming concepts involved. Integrating multiple courses that all have a rigid progression of topics would be exceedingly difficult.

One other component that should not be overlooked is that Mechatronics Engineering is inter-disciplinary at its core. A program which lives at the intersection between Electrical and Computer Engineering and Mechanical Engineering provides for a safe playground to add more integration in topics. Adding a course project that connects the engineering design process, mechanical design, sensors and actuators, and programming is a natural fit as that fully describes the program that the students have chosen. It was a natural connection for the programming instructor to reinforce their teaching by giving a guest lecture in a separate course where programming was involved.

There can be a lot of instructor hesitation to create a truly open-ended learning experience for their students. The fears are typically centered around a perceived inability to keep tabs on what all students are doing, or a fear of being bombarded with questions from lost students about all the dark corners of the discipline that the students have stumbled into. This has not been the experience in MTE 100. Engineering students are more creative than people give them credit for, and providing them with the freedom to explore topics that interest them leads to high levels of engagement. Highly engaged students are much more curious, and are more driven to seek out answers on their own. The conversations that do end up happening with course instructors are some of the most enjoyable interactions instructors can have.

\subsection{Challenges and Lessons Learned}

There were, and still are, many challenges with running and maintaining these integration initiatives. The amount of effort required annually to schedule the $1 \mathrm{~A}$ semester is intense, and has not improved even as the teaching team has gained experience. The schedule cannot be a rigid document either: it is not atypical to be on version 8 or 9 of the schedule by the end of the fall semester. During the semester, regular meetings are a necessity to keeping everyone moving in the same direction, and effort must be spent managing the course TAs (setting precedence in their work tasks, helping them schedule their own time, etc.).

The teaching team has also struggled to control the workload of the course TAs. The fall 2016 semester was the first in recent memory where the TAs were able to maintain about a 2-week turnaround on grading. Typically, by midterm season the TAs are already more than two weeks behind, and continue to fall farther behind as more student work is submitted. MTE 100 has five full time undergraduate co-op students typically hired from within upper years of the Mechatronics program, plus an additional two full time co-ops specifically for GENE 121. Comparing to typical grad student TAs, this would be equivalent to $\sim 24$ TAs at 10 hours/week. The ratio of 7 full time TAs, covering 2.5 courses (MTE 100 is weighted at 1.5 normal courses), for 210 students is similar to the other $1 \mathrm{~A}$ engineering programs at UWaterloo. The changes made in fall 2016 were made in part to address this challenge.

First year engineering programs at UWaterloo also receive strong instructional staff support from a set of Engineering Instructional Support Tutors. These staff members are crucial in carrying continuity from one year to the next. While they don't spend any more hours on one particular course than a grad TA would, because they need limited supervision, and typically handle much of the training of the course TAs, they greatly reduce the load on the course instructors.

There is a large, flexible computer lab at UWaterloo which makes all of this possible as well. This lab hosts nearly all of the integration initiatives in MTE, and is nearing $100 \%$ utilization (Monday to Friday, 8:30am to $8: 30 \mathrm{pm}$ ) in the fall semester. Having a room with enough available equipment, power, computers, and space is critical. The new Engineering 7 building under construction will permanently house the Engineering IDEAs Clinic in a space very similar in design (albeit larger) to this lab, which will alleviate some of the issues we face as the IDEAs Clinic expands faculty-wide.

One common issue identified with integration initiatives is that students must be enrolled in all of the courses being integrated at the same time. This is less of an issue at UWaterloo due to the strong cohort system in place; students enter their $1 \mathrm{~A}$ semester with a class of students and move with that same class of students through the entire program. Having said that, there are typically 36 students who are repeating some, but not all, of the courses that are being integrated. As the courses are strictly separate, with separate assignments, and exams, all that is needed to accommodate these students are alternative assignments to replace the integrated activities that they are not taking part in, or the removal of the activity components from courses they are not taking. In upper years where there is more freedom in course enrollment, or in institutions lacking this strong cohort structure, more work would be required to not disadvantage students who are only taking some of the integrated courses.

One nagging question that plagues the authors of this paper is: Does integration only work because of the instructors involved? If the core instructors were to all leave, would it continue to exist? Would it exist beyond the next course refresh? Looking at other institutions that have tried integrative curricula, few survive more than a decade. Every university is different, but institutionalizing integration appears to be exceedingly difficult. 


\subsection{Successes}

In addition to the successes show in the Results section, there is one further success that is worth speaking to. As Mechatronics is itself an integrated program (Mechanical + Electrical/Computer Engineering), the integrated project and activities that have been added to MTE 100 provide a very authentic picture of the program at a first year level. When a student meets with an instructor to discuss their choice of program, it is easy to point to the different aspects of Mechatronics and ask which parts the student enjoyed the most. The integrated project provides a common reference frame for instructor and student alike. For example, if they liked programming their robot, but didn't like building it, Computer Engineering might be a better choice for them moving forwards. If, however, they liked building the machine, but didn't like programming it, Mechanical Engineering might be a better choice.

\section{CONCLUSIONS}

This paper can make two general conclusions. The $1 \mathrm{~A}$ teaching team have made improvements in regards to the four identified issues with the first semester of the Mechatronics program through the use of integrative activities. The second conclusion is that even small, intervention style activities can create improvements in student engagement and understanding. However, ad hoc integration, as practised by the authors of this paper is only possible due to the inherent flexibility in the host course: MTE 100. One other key factor to the success of these initiatives that is worth restating, is that one student deliverable is graded multiple times for separate courses. This limits any workload increase on the students, and plays the role of the proverbial "spoonful of sugar, that makes the medicine go down".

The authors have one warning for other instructors: integration of course material is time consuming, and even with gains in experience, the time spent on scheduling the semester have not improved.

\section{ACKNOWLEDGEMENTS}

The authors could not have implemented any of these integration initiatives without the support of the Dean of Engineering, Dr. Pearl Sullivan (formerly the Chair of Mechanical Engineering), the current Chair of Mechanical Engineering Dr. Jan Huissoon, the Waterloo Engineering Endowment Foundation (WEEF) through its financial support, and the many, many TAs, instructional staff, and course instructors who have been involved over the many years.

\section{REFERENCES}

[1] E. Li, C. Rennick, C. Hulls, M. CooperStachowsky, E. Boghaert, M. Robinson, W. Melek and S. Bedi, "Tron Days: Horizontal Integration and Authentic Learning," in CEEA Conference, Toronto, 2017.

[2] C. Hulls, C. Rennick, S. Bedi, M. Robinson and W. Melek, "The Use of an Open-Ended Project to Improve the Student Experience in First Year Engineering," in CEEA Conference, Hamilton, 2015.

[3] C. Hulls, C. Rennick, M. Robinson, W. Melek and S. Bedi, "Integrative Activities for First-Year Engineering Students - Fuel Cell Cars as a Linking Project Between Chemistry, Mechatronics Concepts and Programming," in CEEA Conference, 2014, 2014.

[4] J. Baleshta, "Increasing Student Practical Experience with the Hurdle of Large Class Sizes," in CEEA Conference, 2014, 2014.

[5] A. Bright and J. Phillips, "The Harvey Mudd Engineering Clinic Past, Present, Future," Journal of Engineering Education, vol. 88, no. 2, pp. 189-194, 1999.

[6] N. Al-Holou, N. Bilgutay, C. Corleto, J. T. Demel, R. Felder, K. Frair, J. E. Froyd, M. Hoit, J. Morgan and D. L. Wells, "First-Year Integrated Curricula Across Engineering Education Coalitions," in Frontiers in Education Conference, Tempe, 1998.

[7] J. E. Froyd and M. W. Ohland, "Integrated Engineering Curricula," Journal of Enginering Education, vol. 94, no. 1, pp. 147-164, 2005.

[8] P. Ostafichuk, E. Croft, S. Green, G. Schajer and S. Rogak, "Analysis of Mech 2: An AwardWinning Second-Year Mechanical Engineering Curriculum," in Innovation, Good Practice and Research in Engineering Education, 2008.

[9] University of Guelph, "IPS*1500 Integrated Mathematics and Physics I," [Online]. Available: https://www.physics.uoguelph.ca/undergraduatestudies/courses/ips1500. [Accessed April 2017].

[10] The University of British Columbia, "Science One," [Online]. Available: https://scienceone.ubc.ca/. [Accessed April 2017]. 